\section{Thyroid nodules with nondiagnostic results on repeat fine-needle aspiration biopsy: which nodules should be considered for repeat biopsy or surgery rather than follow-up?}

Na Lae Eun', Mi Ri Yoo², Hye Mi Gweon' ${ }^{1}$ Ah Young Park², Jeong-Ah Kim', Ji Hyun Youk', Hee Jung Moon ${ }^{4}$, Hang-Seok Chang ${ }^{5}$, Eun Ju Son ${ }^{1}$

'Department of Radiology, Gangnam Severance Hospital, Yonsei University College of Medicine, Seoul; ${ }^{2}$ Department of Radiology, Dongjak Kyunghee Hospital, Seoul; ${ }^{3}$ Department of Radiology, Korea University Ansan Hospital, Korea University College of Medicine, Ansan; ${ }^{4}$ Department of Radiology and Research Institute of Radiological Science, Severance Hospital, Yonsei University College of Medicine, Seoul; ${ }^{5}$ Department of Surgery, Thyroid Cancer Center, Gangnam Severance Hospital, Yonsei University College of Medicine, Seoul, Korea

Purpose: The goal of this study was to assess the clinicopathologic and ultrasonographic features of thyroid nodules with nondiagnostic results on repeat ultrasonography (US)-guided fineneedle aspiration biopsy (FNAB) according to size and the number of suspicious findings and to determine the proper management of nodules with consecutive nondiagnostic results.

Methods: This retrospective study included 297 nodules with nondiagnostic results on repeat FNAB that were evaluated by US over the course of at least 12 months of follow-up, a follow-up biopsy, or an operation. We compared clinical and US variables between benign and malignant nodules in thyroid nodules with repeat nondiagnostic results.

Results: The comparison of benign and malignant nodules with repeat nondiagnostic results revealed that age, marked hypoechogenicity, irregular or microlobulated margins, microcalcifications, and nonparallel shape were significantly associated with malignancy. Multivariate logistic regression analysis in malignant nodules revealed that microcalcifications and irregular or microlobulated margins were independently associated with malignancy. Among them, only irregular or microlobulated margins were independently significant as a predictor of malignancy in repeatedly nondiagnostic nodules measuring $>10 \mathrm{~mm}$. Using receiver operating characteristic analysis, the best cutoff value for the "number of suspicious findings" between benign and malignant nodules was three in nodules of all sizes, three in nodules measuring $\leq 10$ $\mathrm{mm}$, and two in nodules measuring $>10 \mathrm{~mm}$.

Conclusion: Irregular or microlobulated margins may be the most frequent US features in repeatedly nondiagnostic nodules $>10 \mathrm{~mm}$. The presence of "two or more suspicious findings" can be used as the cutoff for distinguishing benign and malignant nodules.

Keywords: Biopsy, fine-needle; Thyroid nodule; Ultrasonography

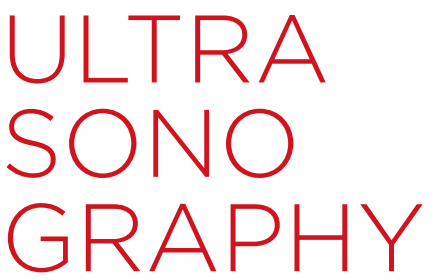

ORIGINAL ARTICLE

http://dx.doi.org/10.14366/usg.15079 pISSN: 2288-5919 • elSSN: 2288-5943 Ultrasonography 2016;35:234-243

Received: November 28, 2015

Revised: February 29, 2016

Accepted: March 6, 2016

Correspondence to:

Eun Ju Son, MD, PhD, Department of Radiology, Gangnam Severance Hospital, Yonsei University College of Medicine, 211 Eonju-ro, Gangnam-gu, Seoul 06273, Korea

Tel. $+82-2-2019-3510$

Fax. +82-2-3462-5472

E-mail: EJSONRD@yuhs.ac

This is an Open Access article distributed under the terms of the Creative Commons Attribution NonCommercial License (http://creativecommons.org/ licenses/by-nc/3.0/) which permits unrestricted noncommercial use, distribution, and reproduction in any medium, provided the original work is properly cited.

Copyright (C) 2016 Korean Society of Ultrasound in Medicine (KSUM)

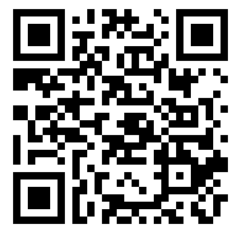

How to cite this article:

Eun NL, Yoo MR, Gweon HM, Park AY, Kim $J A$, Youk JH, et al. Thyroid nodules with nondiagnostic results on repeat fine-needle aspiration biopsy: which nodules should be considered for repeat biopsy or surgery rather than follow-up?. Ultrasonography. 2016 Jul;35(3):234-243. 


\section{Introduction}

Fine-needle aspiration biopsy (FNAB) is considered the standard firstline method of evaluating thyroid nodules, due to its high accuracy and low invasiveness [1-3]. This method has significantly reduced the operation rate for benign nodules. Unfortunately, unsatisfactory or nondiagnostic results present a dilemma for clinicians and radiologists managing thyroid nodules, particularly nodules with high nondiagnostic rates in repeat biopsies or high malignancy rates. The Bethesda System for Reporting Thyroid Cytopathology [4] recommends nondiagnostic rates of ideally less than $10 \%$ of all FNABs; however, up to $21 \%$ of nodules have nondiagnostic results in initial FNAB and up to $50 \%-63 \%$ in repeat biopsies [5-9]. The recommended risk of malignancy of nondiagnostic nodules in the Bethesda system is $1 \%-4 \%$; however, malignancy rates ranging from $2 \%$ to $51 \%$ have been reported $[3,7,10-13]$.

Upon nondiagnostic initial FNAB findings, the American Thyroid Association (ATA), the American Association of Clinical Endocrinologists (AACE), the Associazione Medici Endocrinologi, and the European Thyroid Association $[14,15]$ recommend repeat FNAB or resection for repeatedly nondiagnostic nodules. If initially nondiagnostic nodules still show nondiagnostic results after repeat FNAB, surgery is recommended for solid nodules, and surgery or close observation is recommended for cystic nodules $[14,15]$. However, surgery for all solid nodules is not cost-effective and can cause postoperative morbidity in patients. In order to avoid unnecessary operations, several reports have suggested that conservative management rather than surgery should be considered in low-risk groups because most repeatedly nondiagnostic nodules have benign outcomes $[7,16]$. Moon et al. [17] recommended surgery for nondiagnostic nodules in repeat biopsies showing at least one suspicious feature. However, no studies have yet investigated the association of "the number of suspicious findings" with benignity and malignancy according to size in repeatedly nondiagnostic nodules.

The aim of our study was to investigate the clinicopathologic and ultrasonographic (US) features of thyroid nodules with repeated nondiagnostic results according to their size and the number of suspicious findings and to determine the proper management of nodules with consecutive nondiagnostic results.

\section{Materials and Methods}

\section{Study Population}

This retrospective study was performed from January 2009 to December 2013 at a tertiary referral center. Our institutional review board approved the study and did not require informed consent or patient approval. During that period, 13,193 nodules underwent US-guided FNAB at our institution, of which 1,517 nodules (11.5\%) were reported to have nondiagnostic results according to the Bethesda categorization. A second FNAB was performed on 772 of these nodules, and 477 nodules (61.8\%) once again showed nondiagnostic results. Thyroid nodules were classified as benign or malignant after pathological confirmation during surgery or repeat FNABs. Thyroid nodules that did not show significant changes or decreased in size over the course of at least 12 months of follow-up US were considered clinically benign.

Among 477 nondiagnostic nodules with repeat FNABs, 180

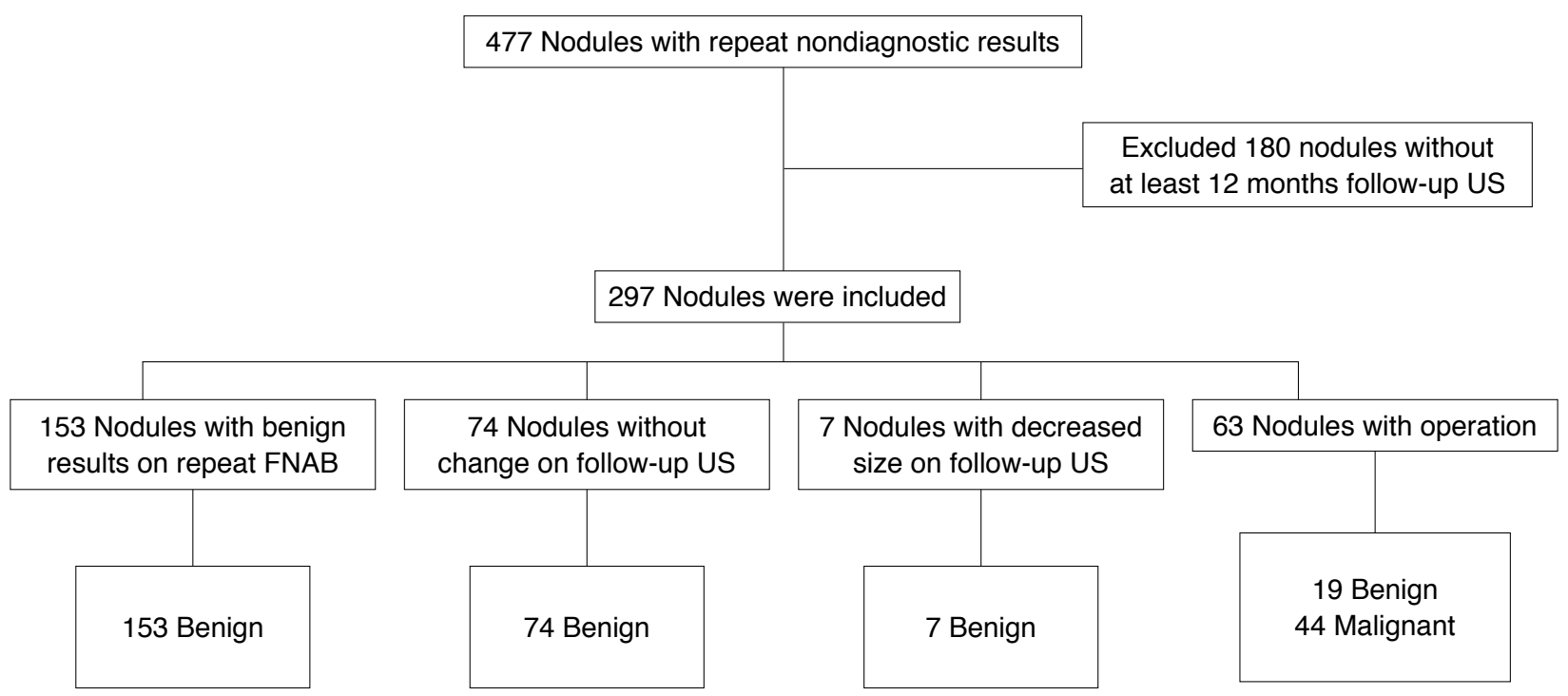

Fig. 1. Study group flow chart. Flow chart shows the process through which thyroid nodules with repeat nondiagnostic results were included in the study. US, ultrasonography; FNAB, fine-needle aspiration biopsy. 
were excluded due to the absence of at least 12 months of followup with US or repeat FNAB. A total of 297 nodules with repeat nondiagnostic results were included in this study; 153 were found to be benign after repeat biopsies, 74 showed no changes during at least 12 months of follow-up US, and seven decreased in size (mean follow-up, 23 months; range, 12 to 70 months), and 63 underwent operation (Fig. 1). Of the total of 297 nodules, 68 were in men and 229 were in women. The mean patient age was 52 years \pm 11 months (range, 23 to 77 years). The mean nodule size was $9.8 \mathrm{~mm}$ (range, 3 to $81 \mathrm{~mm}$ ). Clinical information (patient sex and age at the time of FNAB, and the dates of US), US findings, and cytopathologic records were reviewed for all nodules.

\section{Imaging Methods and US-Guided FNAB}

US and FNA were performed using 7-15 MHz (HDI 5000; Philips Medical Systems, Bothell, WA, USA) and 5-12 MHz linear array transducers (iU22; Philips Medical Systems). Real-time US examinations were performed by one of six radiologists with one to 16 years of thyroid imaging experience. Nodule size was defined as the maximum diameter on US. The US findings of thyroid nodules that underwent FNAB were prospectively analyzed according to internal composition, echogenicity, margin, calcifications, shape, and vascularity at the time of US. The nodules were classified according to internal composition as divided into solid, having a cystic portion of $50 \%$ or less, and having a cystic portion of over $50 \%$. The nodules

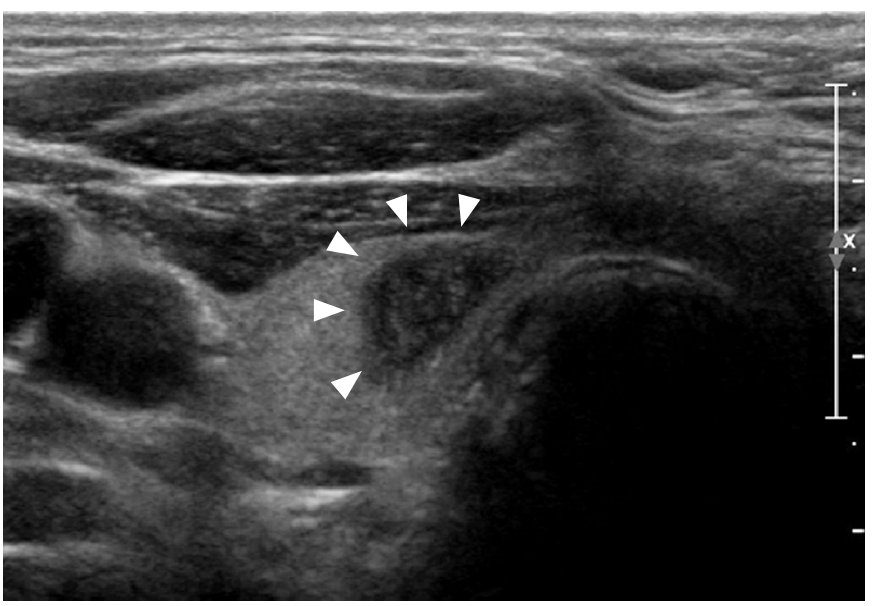

A

Fig. 2. Representive sonograms of thyroid nodules with repeat nondiagnostic results.

A. Transverse sonogram in a 67-year-old man with an 11-mm solid nodule (arrowheads) in the right thyroid gland shows marked hypoechogenicity, microcalcifications, a microlobulated margin, and a taller-than-wide shape. The nodule was repeatedly nondiagnostic, but malignancy was diagnosed upon histopathologic examination after surgery. B. Transverse sonogram in a 57-year-old woman with a 13-mm solid nodule (arrowheads) in the left thyroid gland shows isoechogenicity and a well-defined margin. Biopsy was performed due to ${ }^{18} \mathrm{~F}-2$ fluoro-2-deoxy-D-glucose uptake in positron emission tomography-computed tomography imaging performed as part of follow-up for endometrial cancer. The nodule was repeatedly nondiagnostic but was cytologically diagnosed as benign on the third fine-needle aspiration biopsy. to normal thyroid parenchyma; marked hypoechogenicity was defined as hypoechoic findings in comparison to the strap muscles. The margins were categorized as circumscribed, microlobulated, or irregular. Calcifications were classified as microcalcifications (tiny or punctuate foci measuring less than $1 \mathrm{~mm}$ ), macrocalcifications, or no calcifications. Shape was designated as parallel or nonparallel (taller than wide or greater anteroposterior than transverse direction). Vascularity was divided into peripheral (flow during Doppler US only at the periphery of the nodule), central (flow during Doppler US only in the central portion), both (flow in both sides of the central and peripheral portions), or no vascularity. Suspicious malignant US findings were solidity, marked hypoechogenicity, microcalcifications, microlobulated or irregular margins, and a taller-than-wide shape, in accordance with previous reports (Fig. 2A, B) [18].

The same radiologist who performed the thyroid US performed all US-guided FNABs. FNABs were performed using a free-hand technique and a 23-gauge needle attached to a 2-mL disposable syringe without an aspirator. Each sample was smeared onto several glass slides and immediately alcohol-fixed for Papanicolaou staining. The sample remaining in the syringe was rinsed in saline for cell blocking. Cytologists did not routinely perform on-site evaluations. Pathologists evaluated all nodules according to the Bethesda system.

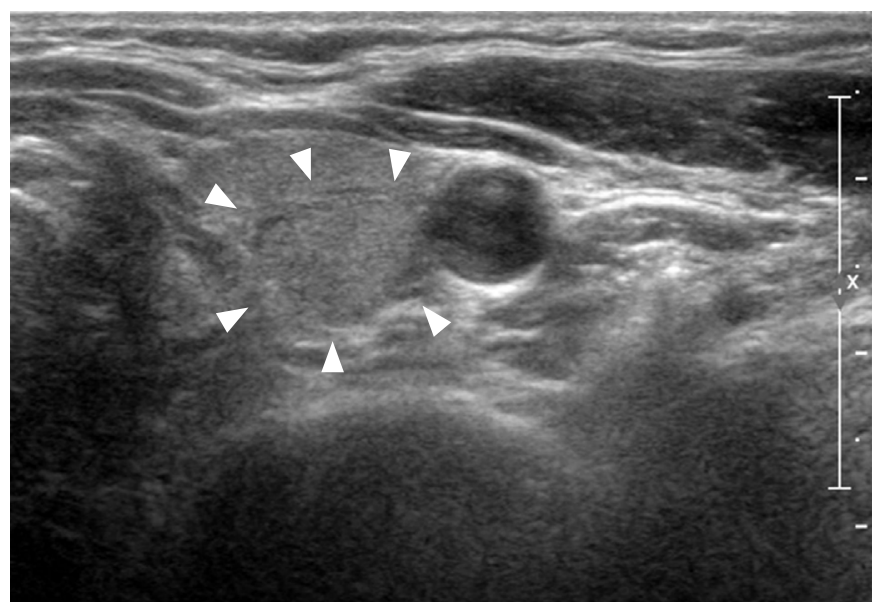

B 


\section{Data and Statistical Analysis}

Thyroid nodules were classified as benign or malignant based on pathological confirmation during surgery or repeat FNABs. Nodules that showed no significant changes or decreased in size over the course of at least 12 months of follow-up US were considered clinically benign.

Categorical data were classified according to percentages and frequencies. We compared malignancy rates, patient characteristics (sex and age), and US characteristics (nodule size, composition, echogenicity, margin, calcification, shape, vascularity, and number of suspicious findings) between benign and malignant nodules in repeatedly nondiagnostic nodules. Continuous variables, including patient age and nodule size, were analyzed using the Student's t test, while categorical variables, including sex, malignancy rates, and US features, were compared using the chi-square test and Fisher exact test. In order to assess independent variables of malignancy in repeatedly nondiagnostic nodules, multivariate logistic regression analysis with a forward stepwise selection method and odds ratios (ORs) was performed. These methods were also used to assess nodules of all sizes, $10 \mathrm{~mm}$ or less, and larger than $10 \mathrm{~mm}[15,19]$.

In addition, receiver operating characteristic (ROC) curves were used to assess the diagnostic value of the number of suspicious findings. The cutoff point was analyzed by a ROC curve, such that the sum of sensitivity and specificity was maximized. The diagnostic sensitivity, specificity, positive predictive value (PPV), negative predictive value (NPV), and accuracy were then determined using the ROC curves. These methods were also used to assess nodules of all sizes, $10 \mathrm{~mm}$ or less, and larger than $10 \mathrm{~mm}$.

Statistical analysis was performed using SAS ver. 9.2 (SAS Institute Inc., Cary, NC, USA). P-values $<0.05$ were considered to indicate statistical significance.

\section{Results}

Among 297 nondiagnostic nodules that underwent repeat FNAB, 44 (14.8\%) were surgically diagnosed as malignant (34 conventional, eight follicular variant, one cystic variant, and one Hürthle cell variant papillary carcinoma), while 253 (85.2\%) were diagnosed as benign. Of 253 benign nodules, 153 were pathologically confirmed as benign on the third through sixth repeat FNABs. Eighty-one nodules showed no change or decreased in size over the course of follow-up US; the other 19 were surgically confirmed as benign (14 cases of adenomatous hyperplasia and five fibrotic nodules).

Marked hypoechogenicity, microlobulated or irregular margins, microcalcifications, and taller-than-wide shape occurred significantly more often in malignant nodules than in benign nodules $(P=0.008$, $\mathrm{P}<0.001, \mathrm{P}<0.001$, and $\mathrm{P}=0.022$, respectively) (Table 1).
Composition and vascularity did not differ significantly between benign and malignant nodules. However, the number of suspicious findings did differ significantly between benign and malignant nodules ( $1.95 \pm 1.12$ vs. $2.82 \pm 1.32$, respectively; $P<0.001$ ) (Table 1). The results of multivariate logistic regression analysis of clinical and US findings in malignant nondiagnostic nodules with repeat nondiagnostic results are shown in Table 2. Microcalcifications (OR, $3.241 ; 95 \%$ confidence interval $[\mathrm{Cl}], 1.504$ to $6.985 ; \mathrm{P}=0.003$ ) and irregular or microlobulated margins $(\mathrm{OR}, 2.35 ; 95 \% \mathrm{Cl}, 1.003$ to $5.539 ; \mathrm{P}=0.049$ ) were independent factors associated with malignant nodules with nondiagnostic results. Of 216 nodules measuring $10 \mathrm{~mm}$ or less, $187(88.6 \%)$ and $24(11.4 \%)$ were benign and malignant, respectively. Marked hypoechogenicity, margin, calcifications, and shape differed significantly between benign and malignant nodules $(P=0.004, P=0.005, P=0.001$, and $P=0.005$, respectively). The number of suspicious findings also differed significantly between benign and malignant nodules $(2.14 \pm 1.12$ vs. $3.24 \pm 1.02$, respectively; $P<0.001)$ (Table 3 ). The results of the multivariate logistic regression analysis of clinical and US findings in malignant nondiagnostic nodules measuring $10 \mathrm{~mm}$ or less are shown in Table 4. Only microcalcifications (OR, 4.715; $95 \% \mathrm{Cl}, 1.841$ to $12.079 ; \mathrm{P}=0.001)$ were an independent factor associated with malignant nodules measuring $10 \mathrm{~mm}$ or less with repeated nondiagnostic results.

Of 81 thyroid nodules larger than $10 \mathrm{~mm}, 66(81.5 \%)$ were benign and $24(18.5 \%)$ were malignant. Only irregular or microlobulated margins were significant US findings $(\mathrm{P}=0.017)$. Other findings, such as composition, echogenicity, calcifications, shape, and vascularity did not differ significantly between benign and malignant nodules larger than $10 \mathrm{~mm}$. The number of suspicious findings was not significantly different between benign and malignant nodules $(1.38 \pm 1.12$, vs. $2 \pm 1.46$, respectively; $P=0.071)$ (Table 5). However, considering the small size of our sample, we were willing to accept that a P-value of 0.071 for the number of suspicious findings can be regarded as a tendency for differentiating between benign and malignant nodules, because P-values less than 0.1 indicate a probable statistical tendency $[20,21]$.

Using the ROC analysis, the best cutoff value for the "number of suspicious findings" between benign and malignant nodules was three in nodules of all sizes (Table 6) and the area under the curve (AUC) was 0.66 (Fig. 3A). Using the best cutoff point, the sensitivity, specificity, PPV, NPV, and accuracy were $65.9 \%, 66.0 \%, 25.21 \%$, $91.76 \%$, and $65.99 \%$, respectively. The best cutoff values were three in nodules $\leq 10 \mathrm{~mm}$ and two in nodules $>10 \mathrm{~mm}$ (Table 6). The AUC values were 0.70 and 0.61 , respectively (Fig. $3 \mathrm{~B}, \mathrm{C}$ ). The sensitivity, specificity, PPV, NPV, and accuracy were $79.31 \%, 60.43 \%, 23.71 \%$, $94.96 \%$, and $62.96 \%$ in nodules $10 \mathrm{~mm}$ or less in size and $60 \%$, 
Table 1. Comparison of malignancy rates with the clinical and ultrasonographic features of repeatedly nondiagnostic thyroid nodules according to malignancy and benignity

\begin{tabular}{|c|c|c|c|}
\hline Characteristic & $\begin{array}{l}\text { Malignant nodule } \\
(\mathrm{n}=44)\end{array}$ & $\begin{array}{c}\text { Benign nodule } \\
(n=253)\end{array}$ & P-value \\
\hline Age (yr) & $49 \pm 10$ & $53 \pm 11$ & 0.032 \\
\hline Sex & & & 0.676 \\
\hline Male & $35 / 44(79.55)^{a)}$ & 194/253 (76.68) & \\
\hline Female & $9 / 44(20.45)$ & $59 / 253(23.32)$ & \\
\hline Nodule size (mm) & $9.89 \pm 8.55$ & $10 \pm 8.46$ & 0.935 \\
\hline Composition & & & 0.380 \\
\hline Solid & $39 / 44(88.64)^{b)}$ & $202 / 253(79.84)$ & \\
\hline Cystic portion $\leq 50 \%$ & $5 / 44(11.36)$ & $41 / 253(16.21)$ & \\
\hline Cystic portion $>50 \%$ & 0/44 (0) & $110 / 253(3.95)$ & \\
\hline Echogenicity & & & 0.008 \\
\hline Hyperechogenicity & $0 / 44(0)$ & 0/253 (0) & \\
\hline Isoechogenicity & $3 / 44(6.82)$ & $51 / 253(20.16)$ & \\
\hline Hypoechogenicity & $30 / 44(68.18)$ & $175 / 253(69.17)$ & \\
\hline Marked hypoechogenicity & $11 / 44(25)$ & $27 / 253(10.67)$ & \\
\hline Margin & & & $<0.001$ \\
\hline Well-defined & 9/44 (20.45) & $118 / 253(46.64)$ & \\
\hline Microlobulated & 6/44 (13.64) & $43 / 253(17)$ & \\
\hline Irregular & 29/44 (65.91) & $92 / 253(36.36)$ & \\
\hline \multicolumn{4}{|l|}{ Calcification } \\
\hline No calcifications & 14/44 (31.82) & $31 / 253(12.25)$ & $<0.001$ \\
\hline Microcalcifications & 5/44 (11.36) & 85/253 (33.6) & \\
\hline Macrocalcifications & $25 / 44(56.82)$ & $137 / 253(54.15)$ & \\
\hline Shape & & & 0.022 \\
\hline Wider than tall & 19/44 (43.18) & $156 / 253(61.66)$ & \\
\hline Taller than wide & $25 / 44(56.82)$ & 97/253 (38.34) & \\
\hline Vascularity & & & 0.799 \\
\hline Peripheral & $13 / 44(29.55)$ & $85 / 253(33.6)$ & \\
\hline Central & $1 / 44(2.27)$ & 6/253 (2.37) & \\
\hline Both & 8/44 (18.18) & $33 / 253(13.04)$ & \\
\hline None & $22 / 44(50)$ & 129/253 (50.99) & \\
\hline No. of suspicious findings & $2.82 \pm 1.32$ & $1.95 \pm 1.12$ & $<0.001$ \\
\hline
\end{tabular}

Values are presented as mean \pm SD or number (\%).

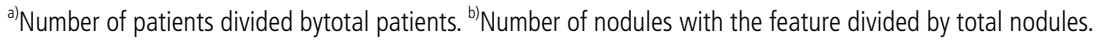

Table 2. Multivariate analysis of clinical and ultrasound characteristics for predicting the malignancy of repeatedly nondiagnostic nodules

\begin{tabular}{lcc}
\hline \multicolumn{1}{c}{ Variable } & OR (95\% Cl) & P-value \\
\hline Echogenicity (marked hypoechogenicity) & $2.034(0.862-4.800)$ & 0.105 \\
Microcalcifications & $3.241(1.504-6.985)$ & 0.003 \\
Margin (irregular/microlobulated) & $2.35(1.003-5.539)$ & 0.049 \\
Shape (nonparallel) & $1.412(0.003-5.539)$ & 0.348 \\
\hline
\end{tabular}

$\mathrm{OR}$, odds ratio; $\mathrm{Cl}$, confidence interval. 
Table 3. Comparison of malignancy rates with the clinical and ultrasonographic features of repeatedly nondiagnostic nodules measuring $10 \mathrm{~mm}$ or less according to malignancy and benignity

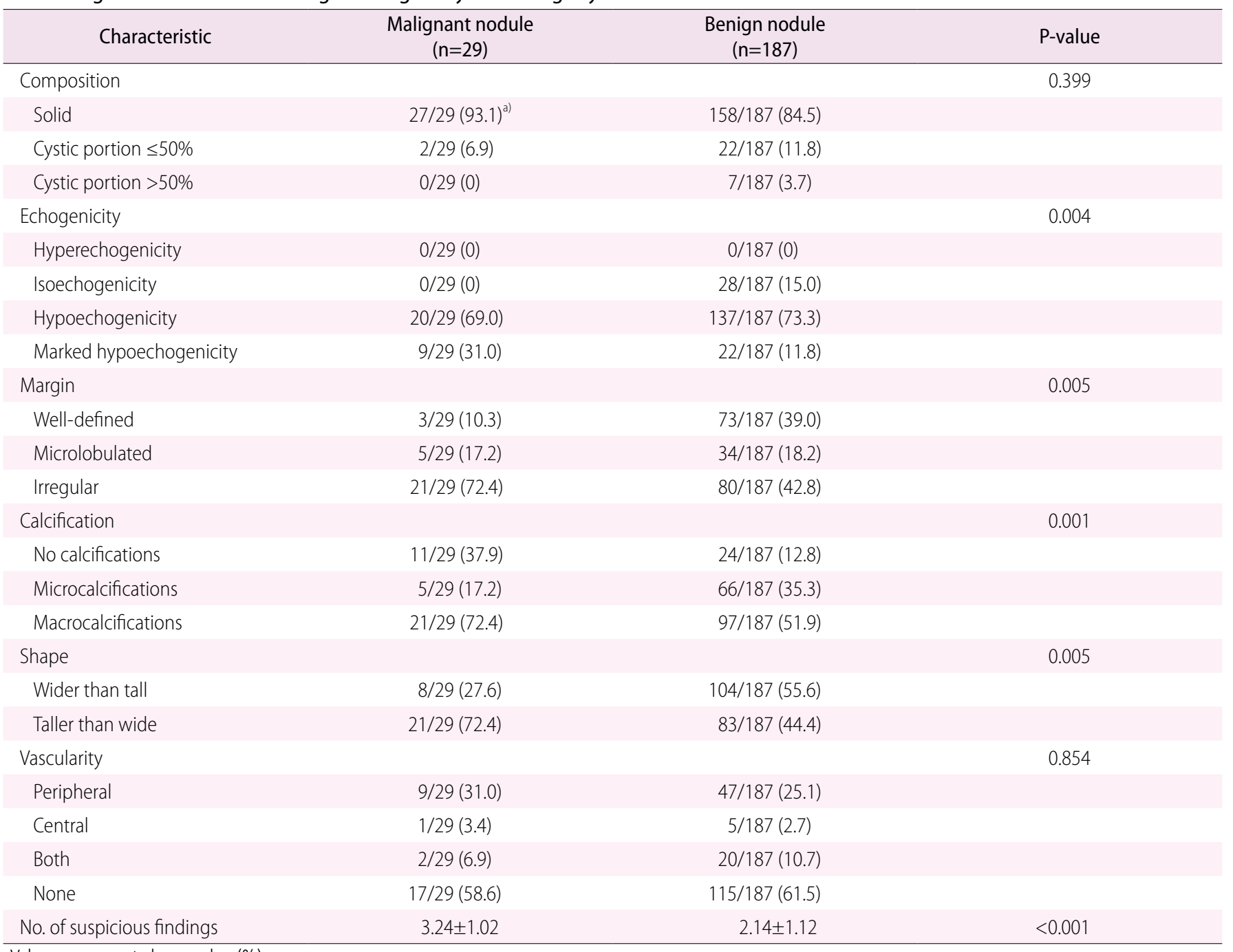

Values are presented as number (\%).

${ }^{a}$ Number of nodules with the feature divided by total nodules.

Table 4. Multivariate analysis of clinical and ultrasound characteristics for predicting malignancy in repeatedly nondiagnostic nodules measuring $10 \mathrm{~mm}$ or less

\begin{tabular}{llc}
\hline \multicolumn{1}{c}{ Variable } & \multicolumn{1}{c}{ OR $(95 \% \mathrm{Cl})$} & P-value \\
\hline Echogenicity (marked hypoechogenicity) & $2.509(0.919-6.846)$ & 0.073 \\
Microcalcifications & $4.715(1.841-12.079)$ & 0.001 \\
Margin (irregular/microlobulated) & $3.414(0.907-12.851)$ & 0.069 \\
Shape (nonparallel) & $2.140(0.826-5.545)$ & 0.117 \\
\hline
\end{tabular}

$\mathrm{OR}$, odds ratio; $\mathrm{Cl}$, confidence interval.

$62.12 \%, 26.47 \%, 87.23 \%$, and $61.73 \%$ in nodules larger than 10 $\mathrm{mm}$, respectively (Table 6).

\section{Discussion}

High nondiagnostic and malignancy rates in repeatedly nondiagnostic nodules present a diagnostic dilemma for clinicians and radiologists, 
Table 5. Comparison of malignancy rates with the clinical and ultrasonographic features of repeatedly nondiagnostic thyroid nodules measuring larger than $10 \mathrm{~mm}$ according to malignancy and benignity

\begin{tabular}{|c|c|c|c|}
\hline Characteristic & $\begin{array}{l}\text { Malignant nodule } \\
(n=15)\end{array}$ & $\begin{array}{l}\text { Benign nodule } \\
(n=66)\end{array}$ & P-value \\
\hline Composition & & & 0.511 \\
\hline Solid & $12 / 15(80.0)^{a)}$ & $44 / 66(66.7)$ & \\
\hline Cystic portion $\leq 50 \%$ & $3 / 15(20.0)$ & 19/66 (28.8) & \\
\hline Cystic portion $>50 \%$ & $0 / 15(0)$ & $3 / 66(4.5)$ & \\
\hline Echogenicity & & & 0.477 \\
\hline Isoechogenicity & $3 / 15(20.0)$ & 23/66 (34.8) & \\
\hline Hypoechogenicity & $10 / 15(66.7)$ & 38/66 (57.6) & \\
\hline Marked hypoechogenicity & 2/15 (13.3) & $5 / 66(7.6)$ & \\
\hline Margin & & & 0.017 \\
\hline Calcification & & & 0.355 \\
\hline No calcifications & $3 / 15(20.0)$ & $7 / 66(10.6)$ & \\
\hline Microcalcifications & 2/15 (13.3) & 19/66 (28.8) & \\
\hline Macrocalcifications & 10/15 (66.7) & 40/66 (60.6) & \\
\hline Shape & & & 0.646 \\
\hline Wider than tall & 11/15 (73.6) & $52 / 66(78.8)$ & \\
\hline Taller than wide & $4 / 15(26.7)$ & $14 / 66(21.2)$ & \\
\hline Vascularity & & & 0.145 \\
\hline Peripheral & $4 / 15(26.7)$ & 38/66 (57.6) & \\
\hline
\end{tabular}

Values are presented as number (\%) or mean \pm SD.

${ }^{a}$ Number of nodules with the feature divided by total nodules.

Table 6. Optimal cutoff values, sensitivity, specificity, predictive values, and accuracy using the number of suspicious findings ${ }^{\text {a) }}$ for differentiating between malignancy and benignity in repeatedly nondiagnostic thyroid nodules

\begin{tabular}{lcccccc}
\hline \multicolumn{1}{r}{ Size } & Cutoff & Sensitivity (\%) & Specificity (\%) & PPV (\%) & NPV (\%) & Accuracy (\%) \\
\hline All & $>2$ & 65.90 & 66.00 & 25.22 & 91.76 & 65.99 \\
$\leq 10 \mathrm{~mm}$ & $>2$ & 79.31 & 60.43 & 23.71 & 94.96 & 62.96 \\
$>10 \mathrm{~mm}$ & $>1$ & 60 & 62.12 & 26.47 & 87.23 & 61.73 \\
\hline
\end{tabular}

PPV, positive predictive value; NPV, negative predictive value.

${ }^{a}$ Suspicious malignant ultrasonographic findings were solidity, marked hypoechogenicity, microcalcifications, microlobulated or irregular margins, and taller-than-wide shape.

who must decide whether to continue repeat FNABs (or surgical intervention) or to perform follow-up US. According to the ATA and AACE guidelines, surgery is recommended for solid nodules and surgery or observation for cystic nodules $[14,15]$. However, surgery for all solid nodules is not cost-effective and can lead to postoperative morbidity in patients. Several studies and guidelines have suggested that nondiagnostic nodules with certain US features be followed up with US rather than repeat biopsies. Yoon et al. 


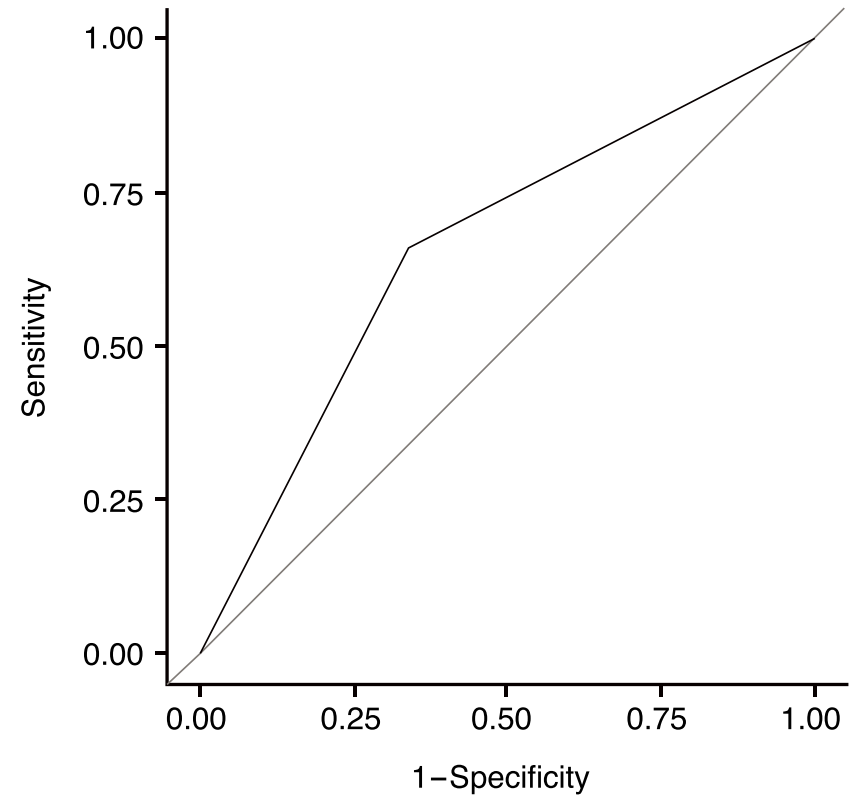

A

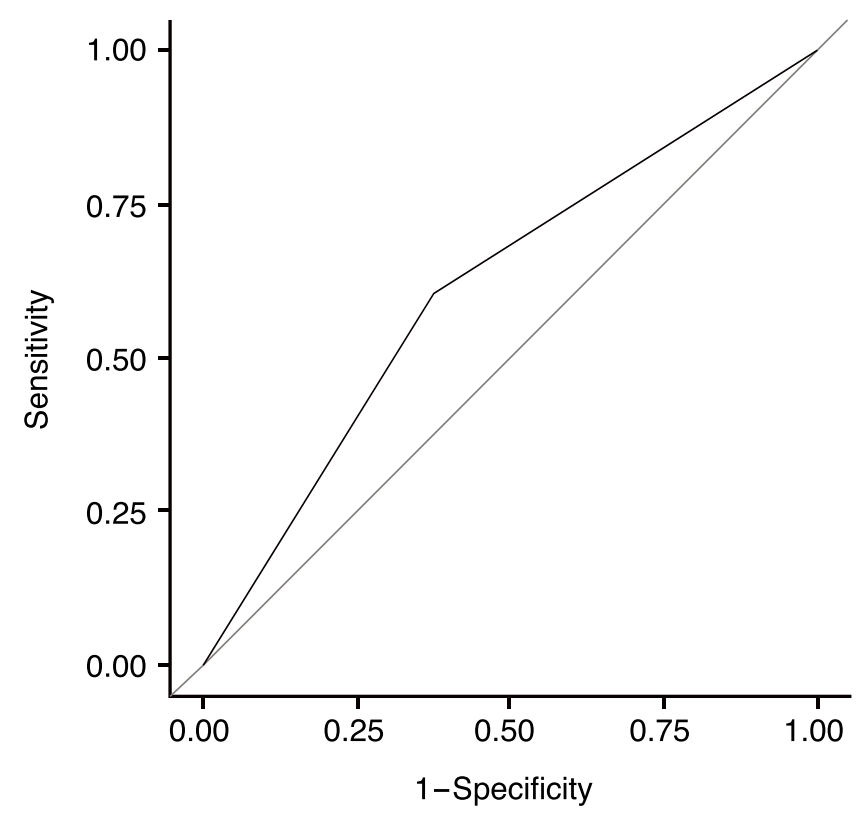

C

[22] proposed that nodules with no suspicious features, especially mainly cystic nodules, should be followed up with US. In our study, none of the nodules with greater than $50 \%$ cystic portions were malignant, consistent with previous findings. Woo et al. [20] recently suggested that hypoechogenicity was an independently significant factor in nodules with repeated nondiagnostic cytology; however, no significant correlation was found in our multivariate analysis.

The results of our study showed that the US features of marked hypoechogenicity, microlobulated or irregular margins, microcalcifications, and nonparallel shape, which have been reported

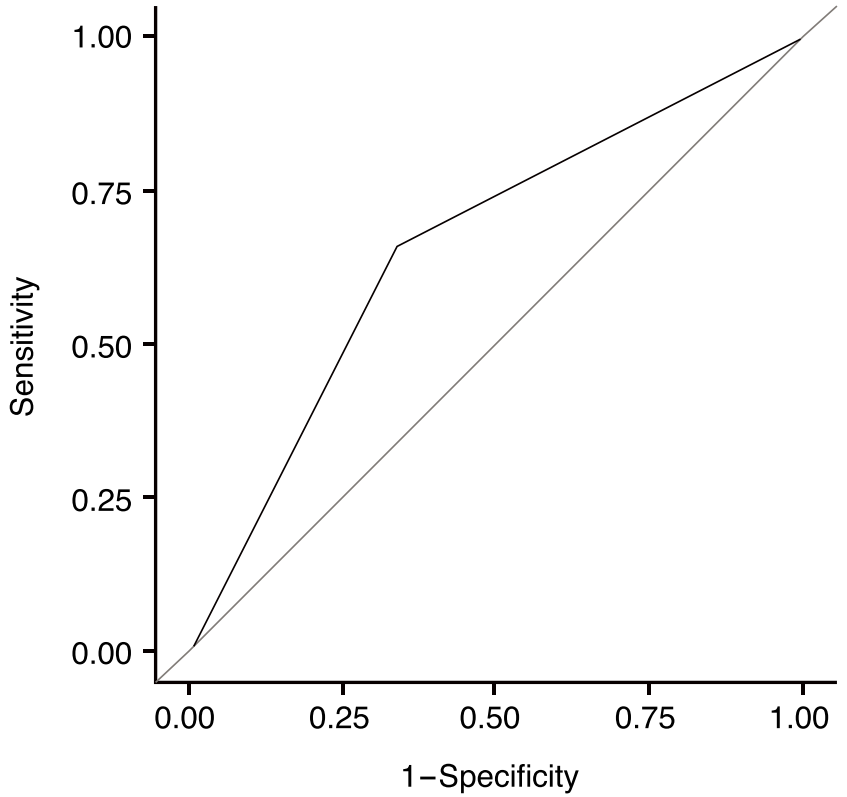

B

Fig. 3. Receiver operating characteristic curves for the number of suspicious findings in the differentiation of malignancy and benignity in repeatedly nondiagnostic thyroid nodules.

A. Area under the curve (AUC) value in nodules with all sizes was 0.66 . B. AUC value in nodules measuring $10 \mathrm{~mm}$ or less was 0.70 . C. AUC value in nodules larger than $10 \mathrm{~mm}$ was 0.61 .

to be significant in a previous study [18], differed significantly between benign and malignant nodules in repeatedly nondiagnostic nodules. Microcalcifications (OR, 3.241; $95 \% \mathrm{Cl}, 1.504$ to 6.985 ; $\mathrm{P}=0.003$ ) and microlobulated or irregular margins (OR, 2.35; 95\% $\mathrm{Cl}, 1.003$ to $5.539 ; \mathrm{P}=0.049$ ) were independent factors predicting malignancy in multivariate regression analysis. Among them, only microcalcifications were found to be significant in a multivariate analysis between benign and malignant nodules measuring $10 \mathrm{~mm}$ or less $(\mathrm{OR}, 4.715 ; 95 \% \mathrm{Cl}, 1.841$ to $12.079 ; \mathrm{P}=0.001)$. In nodules larger than $10 \mathrm{~mm}$, however, only microlobulated or irregular 
margins differed significantly between benign and malignant groups $(P=0.014)$. These discrepancies may be due to the associations between many significant factors in small nodules, in contrast to larger nodules, which showed only one significant finding (microlobulated or irregular margins).

Some authors have proposed that follow-up US is preferable to repeat FNAB and surgery for nondiagnostic nodules $[7,16]$; several reports have suggested that diagnostic options should be evaluated according to US findings $[10,12,17,20]$. Moon et al. [17] recommended surgery for repeatedly nondiagnostic nodules showing one or more suspicious features. Recently, Moon et al. [10] proposed that the Thyroid Imaging Reporting and Data System, developed by Kwak et al. [12], can be used to stratify the risk of malignancy associated with initially nondiagnostic nodules. They concluded that nondiagnostic thyroid nodules without suspicious US features or one suspicious feature can be followed up using US, but those with two or more suspicious features should undergo repeat US-guided FNAB. Our study also showed that the number of suspicious features (including solidity, marked hypoechogenicity, microcalcifications, microlobulated or irregular margins, and tallerthan-wide shape [18]) differed significantly between benign and malignant nodules with repeat nondiagnostic findings $(2.82 \pm 1.32$ vs. $1.95 \pm 1.12$, respectively; $P<0.001$ ), which supports the proposal that the number of suspicious US findings is an important factor in deciding whether to perform follow-up examinations on thyroid nodules with repeatedly nondiagnostic results. In nodules measuring larger than $10 \mathrm{~mm}$, however, the number of suspicious findings was not significantly different between benign and malignant nodules (1.38 \pm 1.12 vs. $2 \pm 1.46$, respectively; $P=0.071)$. However, in light of our small sample size, we considered that a tendency existed for the number of suspicious findings to differentiate benign and malignant nodules $[20,21]$.

In our study, the cutoff value for the number of suspicious findings was three in nodules of all sizes and in those measuring 10 $\mathrm{mm}$ or less, and two in nodules larger than $10 \mathrm{~mm}$. The sensitivity, specificity, PPV, NPV, and accuracy were $65.9 \%, 66.0 \%, 25.21 \%$, $91.76 \%$, and $65.99 \%$ in nodules of all sizes, and $79.31 \%, 60.43 \%$, $23.71 \%, 94.96 \%$, and $62.96 \%$ in nodules $10 \mathrm{~mm}$ in size or smaller and $60 \%, 62.12 \%, 26.47 \%, 87.23 \%$, and $61.73 \%$ in nodules larger than $10 \mathrm{~mm}$, respectively. Although the diagnostic performance was not optimal, we can recommend repeat biopsy or surgery in nodules with two or more suspicious findings to detect malignancy in repeatedly nondiagnostic nodules.

In thyroid nodules with repeatedly nondiagnostic results, the third FNAB is less likely to be diagnostic; however, it can be useful in some patients. Our study showed that 153 out of 477 nodules (32.1\%) were diagnostic. Core-needle biopsy (CNB) can be an alternative to repeat biopsy or surgery in thyroid nodules with prior nondiagnostic results [23-26]. Adjunctive CNB performed along with FNAB showed higher accuracy than FNAB alone $(94 \%$ vs. $82 \%$ ) [25]. The nondiagnostic results ranged from $1.2 \%$ to $26 \%$ of CNBs, which was superior to the results of repeat FNAB [23-26].

To our knowledge, the current study is one of the largest population-based studies of nodules with repeated nondiagnostic cytology. However, our study has several limitations. First, selection bias may have been present, since 795 initially nondiagnostic nodules were excluded due to the lack of a second FNAB and 180 nodules were excluded due to the absence of at least 12 months of follow-up US data. The small proportion of cystic nodules in our study may also have resulted in selection bias. Second, nodules showing no changes in size or decreased size over at least 12 months of follow-up US were considered benign in this study, and some errors may have been present in the malignancy rate because decisions were made regarding surgery or repeat biopsies according to the preferences of the clinicians and/or patients. Third, the AUC values for the "number of suspicious findings" as a criterion for differentiating between benign and malignant nodules were suboptimal (0.61-0.70), making the clinical applicability of these data limited. Fourth, in nodules measuring $>10 \mathrm{~mm}$, the P-value of 0.071 was regarded as indicating a tendency for the number of suspicious findings to differentiate between benign and malignant nodules, considering the small sample size. Further studies with larger population groups should be performed.

In conclusion, irregular or microlobulated margins were the US finding with the greatest ability to predict malignancy in repeatedly nondiagnostic nodules larger than $10 \mathrm{~mm}$. The best cutoff value for distinguishing between benign and malignant nodules was the presence of two or more suspicious findings.

ORCID: Na Lae Eun: http://orcid.org/0000-0002-7299-3051; Mi Ri Yoo: http://orcid. org/0000-0002-7015-7826; Hye Mi Gweon: http://orcid.org/0000-0002-3054-1532; Ah Young Park: http://orcid.org/0000-0002-4747-9480; Jeong-Ah Kim: http://orcid. org/0000-0003-4949-4913; Ji Hyun Youk: http://orcid.org/0000-0002-7787-780X; Hee Jung Moon: http://orcid.org/0000-0002-5643-5885; Hang-Seok Chang: http:// orcid.org/0000-0002-5162-103X; Eun Ju Son: http://orcid.org/0000-0002-78950335

\section{Conflict of Interest}

No potential conflict of interest relevant to this article was reported.

\section{Acknowledgments}

This study was supported in part by the Research Fund of the Korean Society of Ultrasound in Medicine. 


\section{References}

1. Gharib H. Fine-needle aspiration biopsy of thyroid nodules: advantages, limitations, and effect. Mayo Clin Proc 1994;69:44-49.

2. Yokozawa T, Miyauchi A, Kuma K, Sugawara M. Accurate and simple method of diagnosing thyroid nodules the modified technique of ultrasound-guided fine needle aspiration biopsy. Thyroid 1995;5:141-145.

3. Baloch ZW, Sack MJ, Yu GH, Livolsi VA, Gupta PK. Fine-needle aspiration of thyroid: an institutional experience. Thyroid 1998;8:565-569.

4. Cibas ES, Ali SZ; NCI Thyroid FNA State of the Science Conference. The Bethesda System For Reporting Thyroid Cytopathology. Am J Clin Pathol 2009;132:658-665.

5. Alexander EK, Heering JP, Benson CB, Frates MC, Doubilet PM, Cibas ES, et al. Assessment of nondiagnostic ultrasound-guided fine needle aspirations of thyroid nodules. J Clin Endocrinol Metab 2002;87:4924-4927.

6. Baloch Z, LiVolsi VA, Jain P, Jain R, Aljada I, Mandel S, et al. Role of repeat fine-needle aspiration biopsy (FNAB) in the management of thyroid nodules. Diagn Cytopathol 2003;29:203-206.

7. Richards ML, Bohnenblust E, Sirinek K, Bingener J. Nondiagnostic thyroid fine-needle aspiration biopsies are no longer a dilemma. Am J Surg 2008;196:398-402.

8. Baier ND, Hahn PF, Gervais DA, Samir A, Halpern EF, Mueller PR, et al. Fine-needle aspiration biopsy of thyroid nodules: experience in a cohort of 944 patients. AJR Am J Roentgenol 2009;193:11751179.

9. Gharib H, Goellner JR. Fine-needle aspiration biopsy of thyroid nodules. Endocr Pract 1995;1:410-417.

10. Moon HJ, Kim EK, Yoon JH, Kwak JY. Malignancy risk stratification in thyroid nodules with nondiagnostic results at cytologic examination: combination of thyroid imaging reporting and data system and the Bethesda System. Radiology 2015;274:287-295.

11. MacDonald L, Yazdi HM. Nondiagnostic fine needle aspiration biopsy of the thyroid gland: a diagnostic dilemma. Acta Cytol 1996;40:423-428.

12. Kwak JY, Han KH, Yoon JH, Moon HJ, Son EJ, Park SH, et al. Thyroid imaging reporting and data system for US features of nodules: a step in establishing better stratification of cancer risk. Radiology 2011;260:892-899.

13. Chow LS, Gharib H, Goellner JR, van Heerden JA. Nondiagnostic thyroid fine-needle aspiration cytology: management dilemmas. Thyroid 2001;11:1147-1151.

14. Gharib H, Papini E, Paschke R, Duick DS, Valcavi R, Hegedus L, et al. American Association of Clinical Endocrinologists, Associazione Medici Endocrinologi, and European Thyroid Association medical guidelines for clinical practice for the diagnosis and management of thyroid nodules. J Endocrinol Invest 2010;33(5 Suppl):1-50.

15. American Thyroid Association (ATA) Guidelines Taskforce on Thyroid Nodules and Differentiated Thyroid Cancer, Cooper DS, Doherty GM, Haugen BR, Kloos RT, Lee SL, et al. Revised American Thyroid Association management guidelines for patients with thyroid nodules and differentiated thyroid cancer. Thyroid 2009;19:11671214.

16. Anderson TJ, Atalay MK, Grand DJ, Baird GL, Cronan JJ, Beland MD. Management of nodules with initially nondiagnostic results of thyroid fine-needle aspiration: can we avoid repeat biopsy? Radiology 2014;272:777-784.

17. Moon HJ, Kwak JY, Choi YS, Kim EK. How to manage thyroid nodules with two consecutive non-diagnostic results on ultrasonographyguided fine-needle aspiration. World J Surg 2012;36:586-592.

18. Kim EK, Park CS, Chung WY, Oh KK, Kim DI, Lee JT, et al. New sonographic criteria for recommending fine-needle aspiration biopsy of nonpalpable solid nodules of the thyroid. AJR Am J Roentgenol 2002;178:687-691.

19. Shin $Y G$, Kang $H$, Joh $Y D$, Jeong KS, Kim BS. Ultrasonographic features of metastatic lymph nodes in papillary thyroid microcarcinomas and macrocarcinomas. J Korean Soc Radiol 2015;72:92-100.

20. Woo SH, Kim KH, Kim RB. Thyroid nodules with repeat nondiagnostic cytologic results: the role of clinical and ultrasonographic findings. World I Surg 2015;39:1721-1727.

21. Lentner C. Geigy scientific tables. Vol. 2. 8th ed. Basle: Ciba-Geigy Ltd., 1982.

22. Yoon JH, Moon HJ, Kim EK, Kwak JY. Inadequate cytology in thyroid nodules: should we repeat aspiration or follow-up? Ann Surg Oncol 2011;18:1282-1289.

23. Yeon JS, Baek JH, Lim HK, Ha EJ, Kim JK, Song DE, et al. Thyroid nodules with initially nondiagnostic cytologic results: the role of core-needle biopsy. Radiology 2013;268:274-280.

24. Samir AE, Vij A, Seale MK, Desai G, Halpern E, Faquin WC, et al. Ultrasound-guided percutaneous thyroid nodule core biopsy: clinical utility in patients with prior nondiagnostic fine-needle aspirate. Thyroid 2012;22:461-467.

25. Sung JY, Na DG, Kim KS, Yoo H, Lee $H$, Kim JH, et al. Diagnostic accuracy of fine-needle aspiration versus core-needle biopsy for the diagnosis of thyroid malignancy in a clinical cohort. Eur Radiol 2012;22:1564-1572.

26. Na DG, Kim JH, Sung JY, Baek JH, Jung KC, Lee $H$, et al. Coreneedle biopsy is more useful than repeat fine-needle aspiration in thyroid nodules read as nondiagnostic or atypia of undetermined significance by the Bethesda system for reporting thyroid cytopathology. Thyroid 2012;22:468-475. 